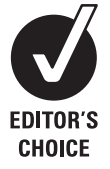

${ }^{1}$ Department of Occupationa Health, University of Milan, Foundation IRCCS Ospedale, Maggiore, Milan, Italy; ${ }^{2}$ MRC Epidemiology Resource Centre Southampton General Hospital, Southampton, UK

Correspondence to:

Professor Keith Palmer, MRC Epidemiology Resource Centre Southampton General Hospital Southampton S016 6YD, UK; ktp@mrc.soton.ac.uk

Accepted 11 March 2009

\title{
Occupational physical activities, working hours and outcome of pregnancy: findings from the Southampton Women's Survey
}

\author{
M Bonzini, ${ }^{1}$ D Coggon, ${ }^{2}$ K Godfrey, ${ }^{2}$ H Inskip, ${ }^{2}$ S Crozier, ${ }^{2}$ K T Palmer ${ }^{2}$
}

\begin{abstract}
Objectives: To investigate risks of physical activity at work by pregnancy trimester, including the effects on head and abdominal circumference.

Method: At 34 weeks of gestation we interviewed 1327 mothers from the prospective Southampton Women's Survey (SWS); we asked about their activities (working hours, standing/walking, kneeling/squatting, trunk bending, lifting and night shifts) in jobs held at each of 11, 19 and 34 weeks of gestation, and subsequently ascertained four birth outcomes (preterm delivery, small for gestational age (SGA) and reduced head or abdominal circumference) blinded to employment history.
\end{abstract}

Results: Risk of preterm delivery was elevated nearly threefold in women whose work at 34 weeks entailed trunk bending for $>1 \mathrm{~h} /$ day. Small head circumference was more common in babies born to women who worked for $>40 \mathrm{~h} /$ week. However, no statistically significant associations were found with SGA or small abdominal circumference, and preterm delivery showed little association with long working hours, lifting, standing or shift work.

Conclusions: There is a need for more research on trunk bending late in pregnancy, and on the relationship of work to reduced head circumference. Our findings on several other occupational exposures common among pregnant workers are reassuring.

In Europe, as in most parts of the world, women of reproductive age make up a substantial proportion of the workforce, and legislation requires employers to assess and, where possible, to minimise the health risks to pregnant workers. ${ }^{1}$

To aid risk assessment we recently undertook a systematic review ${ }^{2}$ of the epidemiological evidence relating five common occupational exposures (prolonged working hours, shift work, lifting, standing and heavy physical workload) to several major adverse outcomes of pregnancy, including preterm delivery and low birth weight. These health endpoints were chosen as determinants of perinatal and infant mortality, ${ }^{34}$ and as predictors of adverse outcomes in later life, such as delayed development, neurological and cognitive deficit, high blood pressure, non-insulin dependent diabetes, coronary heart disease, stroke and obstructive lung disease. ${ }^{5}$ For preterm delivery, we found extensive and generally consistent evidence related to each exposure, and this tended to rule out more than moderate effects (relative risks $(R R)>1.4),{ }^{2}$ a finding supported by a second independent systematic review and meta-analysis. ${ }^{6}$ However, for small for gestational age (SGA), although risk

\section{What this paper adds}

- Few reports of occupational physical activity and adverse pregnancy outcome present risk estimates by birth anthropometry or explore the risks of trunk bending.

- Risk of preterm delivery was elevated threefold in women whose work at 34 weeks entailed trunk bending for $>1 \mathrm{~h} /$ day.

- Small head circumference was more common in babies born to women who worked for $>40 \mathrm{~h} /$ week, but other findings were broadly reassuring.

- More research is needed on trunk bending late in pregnancy, and on the relationship of work to reduced head circumference.

estimates were not dissimilar, the evidence base was smaller. More generally, we found few studies in which risk estimates were presented separately for occupational exposures in different trimesters of pregnancy, although the same activity might carry different risks if it occurred late in pregnancy as compared with only a few weeks after conception. And we highlighted a need for "well-designed cohort studies in which relevant exposures are assessed prospectively at different stages of pregnancy and subsequent health outcomes are systematically ascertained". ${ }^{2}$

Another limitation in the evidence base on occupational activities relates to birth anthropometrics. Small head circumference at birth can be related to higher blood pressure in childhood ${ }^{7}$ and adulthood, ${ }^{8}$ impaired glucose tolerance, ${ }^{9}$ and a higher prevalence and mortality from cardiovascular disease, ${ }^{10}{ }^{11}$ while lower abdominal circumference at birth predicts raised serum concentrations of blood lipids in later life. ${ }^{12}$ However, occupational studies have almost never considered head or abdominal circumference as clinical outcomes in their own right.

To address these various gaps in the evidence base we conducted a cohort study with exposures defined for different trimesters of pregnancy and outcomes encompassing birth anthropometrics as well as SGA and preterm delivery.

\section{METHODS}

Our study used data from the Southampton Women's Survey (SWS), a longitudinal study that aimed to recruit all women aged $20-34$ years, who 
Table 1 Characteristics of study cohort

\begin{tabular}{lccl}
\hline & Mean & SD & Range \\
\hline Maternal age (years) & 30.3 & 3.8 & $20.8-38.5$ \\
Maternal BMl before pregnancy & 25.4 & 4.8 & $16.2-48.9$ \\
Infant birth weight (g) & 3495 & 478 & $1676-5296$ \\
Infant head circumference (cm) & 35.0 & 1.3 & $30.0-38.7$ \\
Infant abdominal circumference (cm) & 33.5 & 1.7 & $25.9-39.4$ \\
\hline \multicolumn{3}{c}{ No (\%) } \\
\hline
\end{tabular}

\section{Female baby}

Mother consumed $\geqslant 14$ units of alcohol

$621(47)$

per week before pregnancy

Mother smoked before pregnancy

$267(20)$

Maternal educational level

No qualifications

CSE or equivalent

0 level or equivalent

A level or equivalent

HND or equivalent

Degree

Primiparous

Mother worked at 11 weeks of gestation

Mother worked at 19 weeks of gestation

Mother worked at 34 weeks of gestation

Preterm delivery

Small for gestational age

Small head circumference

Small abdominal circumference

BMl, bodymass index.

were resident in the city of Southampton, England during $1998-2002 \cdot{ }^{13}$ At entry to the SWS, each of the 12583 participants was interviewed and examined by a research nurse, and those who subsequently became pregnant were followed up with further interviews at 11 and 34 weeks of gestation. Details of the birth were then abstracted from obstetric records, and anthropometric measurements were made on the new-born babies.

The analysis presented in this paper focused on singleton pregnancies leading to a live birth between 1 June 1999 and 31 December 2003, after more than 34 weeks of gestation, in Caucasian women who did not have diabetes or pre-eclampsia, and who undertook paid employment at some time during pregnancy. Where a woman had more than one baby during this period, only the first eligible pregnancy was included.

From the interview and examination at entry to the SWS, we obtained information about the mother's date of birth, alcohol consumption, smoking habits, education, parity, height and weight. Alcohol consumption was classified into two bands $(<14$ and $\geqslant 14$ units per week), and education was graded in six levels according to the highest academic qualification obtained. Height was measured to the nearest millimetre with a stadiometer, and weight to the nearest $0.1 \mathrm{~kg}$ with an electronic scales (after removal of shoes and heavy clothing). These measurements were used to calculate body mass index (BMI).

Occupational activities during pregnancy were ascertained through the interview conducted at 34 weeks of gestation. Women were asked whether they were in paid work at each of 11, 19 and 34 weeks of gestation; and where they had held jobs at one or more of these times, they were asked how many hours per week they worked, whether the work included night shifts, and whether or not an average day at work involved each of four physical activities (standing or walking for more than $4 \mathrm{~h}$ in total, kneeling or squatting for more than an hour in total, standing or sitting with the trunk bent forward (illustrated in a diagram) for more than an hour in total, and lifting or carrying weights of $25 \mathrm{~kg}$ or more by hand).

Data abstracted from hospital records at birth included the baby's sex and birth weight. We collected detailed menstrual and ultrasound data in early pregnancy ${ }^{13}$ and set the estimated date of conception using an algorithm that combined menstrual and ultrasound data. Deliveries were classed as preterm if they occurred before 260 days (37 weeks) of gestation. Birth weights were measured with digital scales, and babies were classed as SGA if, after account was taken of gestational age and sex, the weight was in the lowest $10 \%$ of the standard British distribution in $1990 .{ }^{14}$

In addition to the abstraction of these routinely recorded clinical data, a research nurse from the study team measured the baby's head circumference and upper abdominal circumference (at the level of the xiphisternum) within $48 \mathrm{~h}$ of birth. These measurements were made to the nearest millimetre with a tape measure, using a standardised technique. Head circumference was assessed against the standard British distribution in 1990, according to gestational age and sex. ${ }^{14}$ For abdominal circumference there were no satisfactory external reference values, and the expected sex-specific distribution by gestational age was therefore derived by applying random-effects regression to internal SWS data using the method of Royston. ${ }^{15}$ Small head and abdominal circumference were defined as being below the 10th centile of the reference population.

Statistical analysis was carried out with Stata 10.0 software. Risk factors for each of four adverse outcomes of pregnancy

Table 2 Associations of birth outcomes with non-occupational risk factors

\begin{tabular}{|c|c|c|c|c|c|c|c|c|}
\hline \multirow[b]{2}{*}{ Risk factor } & \multicolumn{2}{|l|}{ Preterm delivery } & \multicolumn{2}{|c|}{ Small for gestational age } & \multicolumn{2}{|c|}{ Small head circumference } & \multicolumn{2}{|c|}{ Small abdominal circumference } \\
\hline & $\mathrm{OR}^{*}(95 \% \mathrm{Cl})$ & p Value & $O R^{*}(95 \% \mathrm{Cl})$ & p Value & $\mathrm{OR}^{*}(95 \% \mathrm{Cl})$ & p Value & $O R^{*}(95 \% \mathrm{Cl})$ & p Value \\
\hline Maternal age $\uparrow$ & $1.01(0.93$ to 1.10$)$ & 0.8 & 1.04 (0.98 to 1.11$)$ & 0.2 & $0.99(0.95$ to 1.04$)$ & 0.8 & $1.05(1.00$ to 1.10$)$ & 0.07 \\
\hline $\begin{array}{l}\text { Consumed } \geqslant 14 \text { units of alcohol } \\
\text { per week before pregnancy }\end{array}$ & $0.73(0.33$ to 1.63$)$ & 0.4 & $1.23(0.74$ to 2.04$)$ & 0.4 & 0.81 (0.50 to 1.31 ) & 0.4 & 1.00 (0.64 to 1.57$)$ & 1.0 \\
\hline Smoked before pregnancy & $0.63(0.29$ to 1.36$)$ & 0.2 & 1.59 (0.98 to 2.58$)$ & 0.06 & 1.08 (0.71 to 1.65$)$ & 0.7 & $1.43(0.94$ to 2.17$)$ & 0.09 \\
\hline Educational level§ & $0.89(0.70$ to 1.12$)$ & 0.3 & 0.90 (0.75 to 1.07 ) & 0.2 & 0.87 (0.75 to 1.01$)$ & 0.07 & 0.93 (0.81 to 1.08$)$ & 0.3 \\
\hline Maternal BMI before pregnancy & $0.96(0.89$ to 1.03$)$ & 0.2 & $0.94(0.89$ to 1.00$)$ & 0.04 & 0.98 (0.94 to 1.02 ) & 0.3 & 0.99 (0.95 to 1.03$)$ & 0.7 \\
\hline
\end{tabular}

\footnotetext{
*For each outcome, all risk factors were examined in a single logistic regression model, and odds ratios are therefore mutually adjusted.

† Maternal age was analysed as a continuous variable. Risk estimates are for a 1-year increase in age.

$\sharp$ Not applicable because outcome was adjusted for the sex of the baby.

§Educational level was analysed as an ordinal variable with six levels defined as in table 1. Risk estimates are for an increase of one level.

- Maternal BMI was analysed as a continuous variable. Risk estimates are for an increase of $1 \mathrm{~kg} / \mathrm{m}^{2}$.

BMl, bodymass index.
} 
Table 3 Associations of preterm delivery with occupational activities

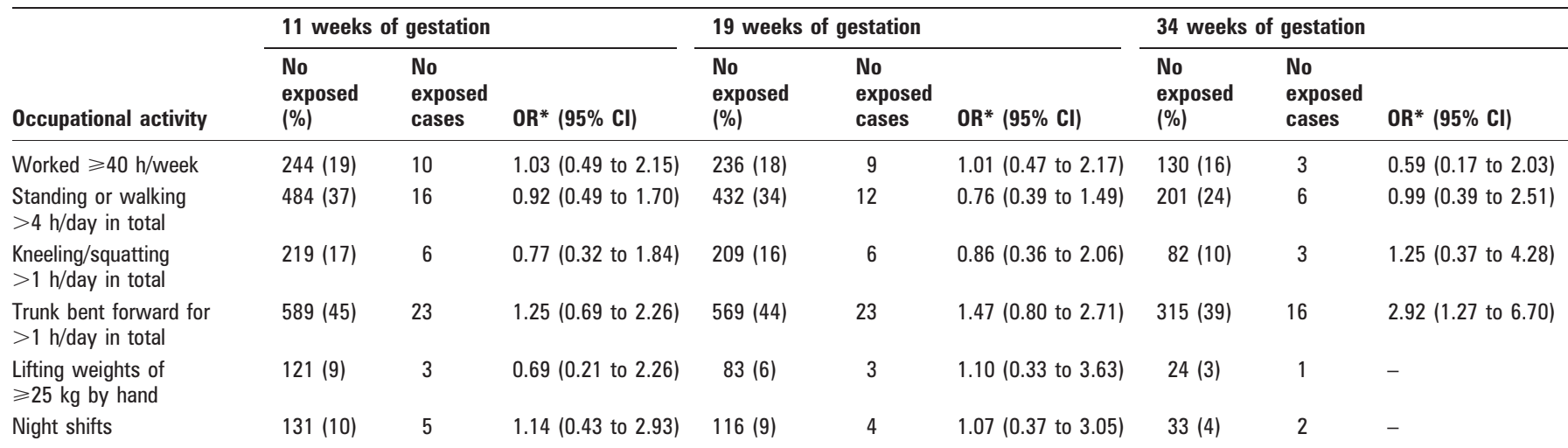

*Each risk factor was examined in a separate logistic regression model with adjustment for primiparity. Risk estimates are for those exposed to the risk factor relative to those who were in work at the relevant stage of pregnancy but unexposed.

(preterm delivery, SGA, small head circumference and small abdominal circumference) were examined by logistic regression, and associations were summarised by odds ratios (ORs) and associated 95\% confidence intervals (CIs). We first explored associations with non-occupational risk factors, using a single regression model for each adverse outcome. Variables that were associated with an outcome $(p<0.2)$ were then carried forward as factors of adjustment in subsequent analyses of occupational risk factors.

Having assessed the risk of each outcome according to whether or not the mother was in any form of work at 34 weeks of gestation, we examined associations with exposure to specific occupational activities at three different points in pregnancy (11, 19 and 34 weeks). In these analyses, we compared women who were exposed to an activity with those who were in work at the same stage of pregnancy but unexposed to the activity. Each activity was analysed independently with adjustment for potential non-occupational confounders.

Finally, to address the possibility that some women may have ceased one or more occupational activities because of early complications of pregnancy, we looked for evidence of healthy worker selection by comparing mothers who carried out an occupational activity at 34 weeks of gestation with mothers who were in work at 34 weeks of gestation but had not been exposed to the activity at any stage of pregnancy.

\section{RESULTS}

A total of 1327 pregnancies met the criteria for inclusion in our analysis (table 1). The ages of the mothers ranged from 21 to 38 years (mean 30 years), and 54\% were primiparous. Almost all were in paid work at 11 and 19 weeks of gestation, and 797 $(60 \%)$ were working at 34 weeks of gestation. Preterm delivery occurred in $46(3 \%)$ pregnancies, and $89(7 \%)$ babies were SGA.

Table 2 shows the relationship of birth outcomes to the nonoccupational risk factors examined. The strongest associations were for primiparity with SGA (OR 2.62, 95\% CI 1.55 to 4.42 ) and small abdominal circumference (OR 2.22, 95\% CI 1.46 to 3.37). In addition, weaker associations (but with $p<0.2$ ) were observed for maternal age, pre-pregnancy BMI and smoking with SGA; primiparity and maternal educational level with small head circumference; and maternal age and smoking with small abdominal circumference. These variables were therefore carried forward as factors of adjustment when examining occupational risk factors.

In comparison with mothers who had stopped working before 34 weeks of gestation, those who remained in employment showed no statistically significant differences in the risk of adverse birth outcomes. After adjustment for potential confounding factors, the odds ratios were 0.76 (95\% CI 0.41 to 1.37) for preterm delivery, 1.25 ( $95 \%$ CI 0.79 to 1.99 ) for SGA, 1.04 (95\% CI 0.72 to 1.51 ) for small head circumference, and 1.21 (95\% CI 0.82 to 1.77 ) for small abdominal circumference.

Table 4 Associations of low birth weight (small for gestational age) with occupational activities

\begin{tabular}{|c|c|c|c|c|c|c|c|c|c|}
\hline \multirow[b]{2}{*}{ Occupational activity } & \multicolumn{3}{|c|}{11 weeks of gestation } & \multicolumn{3}{|c|}{19 weeks of gestation } & \multicolumn{3}{|c|}{34 weeks of gestation } \\
\hline & $\begin{array}{l}\text { No } \\
\text { exposed } \\
(\%)\end{array}$ & $\begin{array}{l}\text { No } \\
\text { exposed } \\
\text { cases }\end{array}$ & $O R^{*}(95 \% \mathrm{Cl})$ & $\begin{array}{l}\text { No } \\
\text { exposed } \\
(\%)\end{array}$ & $\begin{array}{l}\text { No } \\
\text { exposed } \\
\text { cases }\end{array}$ & $\mathrm{OR}^{*}(95 \% \mathrm{CI})$ & $\begin{array}{l}\text { No } \\
\text { exposed } \\
(\%)\end{array}$ & $\begin{array}{l}\text { No } \\
\text { exposed } \\
\text { cases }\end{array}$ & $\mathbf{O R}^{*}(95 \% \mathrm{Cl})$ \\
\hline $\begin{array}{l}\text { Standing or walking } \\
>4 \mathrm{~h} / \text { day in total }\end{array}$ & $476(36)$ & 31 & 0.93 (0.59 to 1.46 ) & $425(33)$ & 30 & 1.06 (0.67 to 1.69 ) & $196(24)$ & 13 & 0.86 (0.45 to 1.64$)$ \\
\hline $\begin{array}{l}\text { Kneeling/squatting } \\
>1 \mathrm{~h} / \text { day in total }\end{array}$ & $218(17)$ & 16 & 1.21 (0.68 to 2.15 ) & $208(16)$ & 14 & 1.10 (0.60 to 2.00$)$ & $81(10)$ & 6 & $1.06(0.43$ to 2.60$)$ \\
\hline $\begin{array}{l}\text { Lifting weights of } \\
\geqslant 25 \mathrm{~kg} \text { by hand }\end{array}$ & $121(9)$ & 9 & 1.09 (0.53 to 2.27 ) & $83(7)$ & 6 & 1.06 (0.44 to 2.55$)$ & $24(3)$ & 2 & - \\
\hline Night shifts & $130(10)$ & 8 & 0.92 (0.43 to 1.97 ) & $114(9)$ & 7 & 0.92 (0.41 to 2.06 ) & $32(4)$ & 2 & - \\
\hline
\end{tabular}

*Each risk factor was examined in a separate logistic regression model with adjustment for maternal age, primiparity and maternal BMI and smoking before pregnancy, all classified as in table 2. Risk estimates are for those exposed to the risk factor relative to those who were in work at the relevant stage of pregnancy but unexposed. 
Table 5 Associations of small head circumference with occupational activities

\begin{tabular}{|c|c|c|c|c|c|c|c|c|c|}
\hline \multirow[b]{2}{*}{ Occupational activity } & \multicolumn{3}{|c|}{11 weeks of gestation } & \multicolumn{3}{|c|}{19 weeks of gestation } & \multicolumn{3}{|c|}{34 weeks of gestation } \\
\hline & $\begin{array}{l}\text { No } \\
\text { exposed } \\
\text { (\%) }\end{array}$ & $\begin{array}{l}\text { No } \\
\text { exposed } \\
\text { cases }\end{array}$ & $\mathrm{OR}^{*}(95 \% \mathrm{Cl})$ & $\begin{array}{l}\text { No } \\
\text { exposed } \\
\text { (\%) }\end{array}$ & $\begin{array}{l}\text { No } \\
\text { exposed } \\
\text { cases }\end{array}$ & $\mathrm{OR}^{*}(95 \% \mathrm{Cl})$ & $\begin{array}{l}\text { No } \\
\text { exposed } \\
\text { (\%) }\end{array}$ & $\begin{array}{l}\text { No } \\
\text { exposed } \\
\text { cases }\end{array}$ & $\mathrm{OR}^{*}(95 \% \mathrm{Cl})$ \\
\hline $\begin{array}{l}\text { Standing or walking } \\
>4 \mathrm{~h} / \text { day in total }\end{array}$ & $475(36 \%)$ & 57 & $1.40(0.97$ to 2.02$)$ & $423(33 \%)$ & 51 & 1.36 (0.94 to 1.98$)$ & $195(24 \%)$ & 21 & 1.16 (0.68 to 1.97$)$ \\
\hline $\begin{array}{l}\text { Kneeling/squatting } \\
>1 \mathrm{~h} / \text { day in total }\end{array}$ & $216(17 \%)$ & 22 & $1.02(0.63$ to 1.65$)$ & $206(16 \%)$ & 20 & 0.95 (0.57 to 1.58 ) & $79(10 \%)$ & 8 & $1.02(0.47$ to 2.21$)$ \\
\hline $\begin{array}{l}\text { Lifting weights of } \\
\geqslant 25 \mathrm{~kg} \text { by hand }\end{array}$ & $120(9 \%)$ & 18 & 1.64 (0.96 to 2.81$)$ & $82(6 \%)$ & 13 & 1.71 (0.91 to 3.19 ) & $23(3 \%)$ & 5 & $2.52(0.90$ to 7.10$)$ \\
\hline Night shifts & $129(10 \%)$ & 8 & 0.59 (0.28 to 1.24$)$ & $114(9 \%)$ & 5 & 0.41 (0.16 to 1.03 ) & $32(4 \%)$ & 0 & - \\
\hline
\end{tabular}

*Each risk factor was examined in a separate logistic regression model with adjustment for educational level and primiparity, both classified as in table 2. Risk estimates are for those exposed to the risk factor relative to those who were in work at the relevant stage of pregnancy but unexposed.

Risk of preterm delivery was elevated in women whose work entailed sitting or standing with the trunk bent forward for more than an hour per day (table 3), and this association was particularly strong when the activity occurred at 34 weeks of gestation (OR 2.92, 95\% CI 1.27 to 6.70). Other occupational activities showed no clear relation to preterm delivery.

Tables 4-6 summarise the relationships of occupational activities to SGA, small head circumference and small abdominal circumference. No statistically significant associations were seen with SGA or small abdominal circumference, all ORs being less than 1.4. However, small head circumference was more common in babies born to women who worked for $>40 \mathrm{~h}$ per week (ORs 1.51 to 1.72). In addition, there was a suggestion of an increased risk of small head circumference in relation to standing or walking for $>4 \mathrm{~h}$ per day during the first two trimesters (ORs 1.36 to 1.40), and in relation to lifting weights of $>25 \mathrm{~kg}$ by hand, and especially in the last trimester (ORs 1.64 to 2.52 ). However, these findings did not reach statistical significance.

To explore possible healthy worker effects, we repeated the analyses for women who were in work at 34 weeks of gestation, comparing those who carried out an activity late in pregnancy with those who had not been exposed to the activity at any of 11, 19 or 34 weeks of gestation.

This analysis confirmed the association between preterm delivery and sitting or standing with the trunk bent forward (OR 2.66, 95\% CI 1.15 to 12.6). A relationship between small head circumference and working more than $40 \mathrm{~h}$ a week was again observed but did not quite reach statistical significance at the $5 \%$ level (OR 1.71, 95\% CI 0.94 to 3.11 ).

\section{DISCUSSION}

Our findings suggest an increased risk of preterm delivery in women whose work entails trunk bending for $>1 \mathrm{~h}$ per day, especially after 34 weeks of gestation, and of low head circumference in women working $>40 \mathrm{~h}$ per week during pregnancy. However, in keeping with our earlier review, preterm delivery showed little association with prolonged working hours, lifting or standing, and the RR for shift work was similar to the previous pooled estimate of 1.20 to $1.26^{2}$

The present study had the advantage of a prospective design, with exposures assessed pre-delivery and outcomes ascertained objectively, with reasonable precision of measurement and blinding to occupational history. Relevant personal risk factors that could confound associations (such as smoking and maternal BMI) were ascertained before pregnancy and controlled for where relevant in subsequent analysis. Risk estimates were also presented separately for exposures in each trimester of pregnancy, whereas in our earlier review we rarely found reporting at this level of detail. ${ }^{16-19}$ And finally, we studied some clinically important outcomes for which there is almost no occupational risk information (head and abdominal circumference), as well as at least one occupational exposure for which research on adverse pregnancy outcomes appears very sparse (trunk bending).

Table 6 Associations of small abdominal circumference with occupational activities

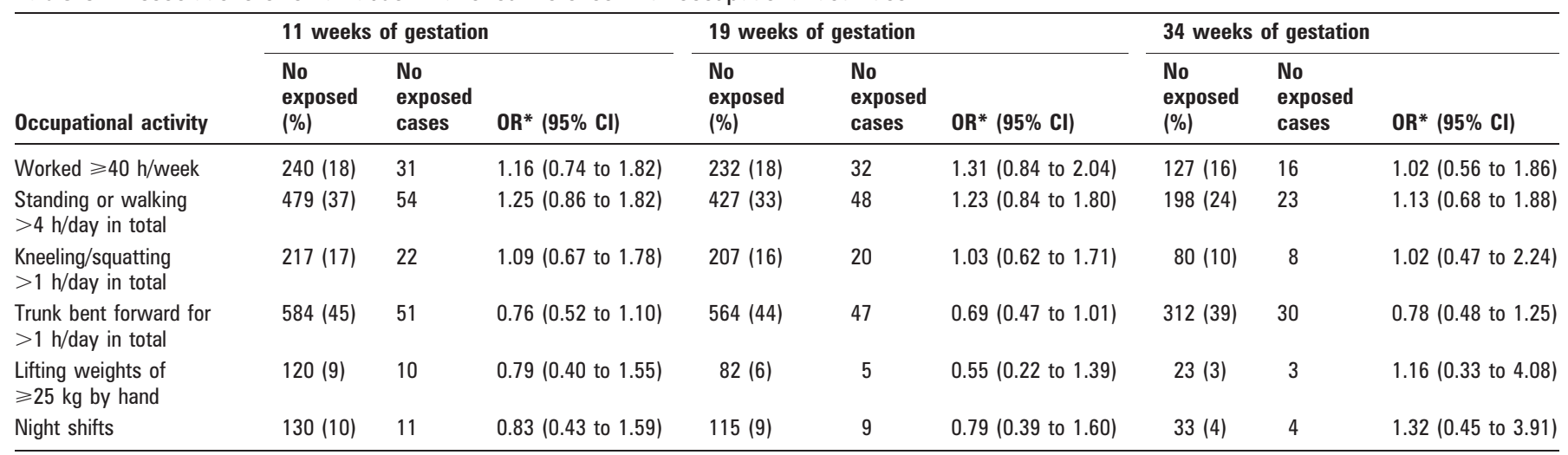

*Each risk factor was examined in a separate logistic regression model with adjustment for maternal age, smoking and primiparity, all classified as in table 2 . Risk estimates are for those exposed to the risk factor relative to those who were in work at the relevant stage of pregnancy but unexposed. 
One limitation of our investigation was the reliance on selfreported exposures, with the possibility of either differential or non-differential measurement error. The former appears less likely, however, as exposures were ascertained before outcomes. The latter may be greater for exposures that are difficult to selfestimate, such as weights lifted or time spent standing, than for those that are simpler to judge (eg, working hours, night shift working). However, non-differential measurement error is unlikely to explain the positive associations that we observed.

A second limitation was our capacity to assess exposures only by questions at the 34-week interview, without tracking job changes and their reasons. Healthy worker selection bias could arise if women with complications of pregnancy dropped out of work altogether, or changed the work they did, to avoid certain activities. The likely impact would be to obscure risks of work later in pregnancy, and once again such bias to the null would not explain the positive associations of preterm delivery with truck bending. Similarly, the elevated risk of small head circumference, which was apparent in relation to prolonged working hours in each of the trimesters, requires an alternative explanation.

Of more concern in the context of healthy worker selection bias is the interpretation of null findings, such as the lack of association between standing and preterm delivery. In the main analyses we compared women who were exposed to a given activity with those who were in work at the same stage of pregnancy but not exposed to that activity. To explore the impact of selection effects, we also conducted a sensitivity analysis comparing mothers who carried out an occupational activity at 34 weeks of gestation with mothers who were in work at that stage but had not been exposed to the activity at any stage of pregnancy. The associations between trunk bending and preterm delivery and between working hours and small head circumference were little changed, suggesting that healthy worker selection did not have a strong influence on the findings. In principle, our comparison group (women in work at the same stage of pregnancy but unexposed to a given occupational activity) could have been exposed to other occupational activities that confer risk. If so, then the risk of preterm delivery with trunk bending in late pregnancy would be underestimated. In practice, however, any bias is likely to be small given evidence from our previous systematic review ${ }^{2}$ and from the current analysis that the exposures in question are relatively weak risk factors.

A third limitation of our study concerns the power to detect associations in a relatively healthy cohort (outcome prevalences 3-10\%) among whom exposures such as night shift work and lifting were reported by $\leqslant 10 \%$ of women. This meant that for some of the exposures investigated, 95\% CIs were relatively wide. Thus, for example, although night shift work at 11 weeks of gestation was associated with a $14 \%$ increase in risk of preterm delivery (five exposed cases), the $95 \%$ confidence limits were compatible with a $57 \%$ protective effect or a near tripling of risks. Other exposures, such as standing or walking and trunk bending, were more common (24-45\%), however, allowing risks to be estimated with greater precision.

The stepwise selection strategy used in our analysis, which was based upon statistical significance testing, could in theory discard factors showing strong but imprecise associations, but no factor with these characteristics was omitted (table 2) and in practice, such a factor would most probably have a low prevalence and a limited potential to confound.

Finally, it should be noted that our entry criterion for analysis, which required interview data at 34 weeks of gestation, precluded exploration of the risks of early fetal loss, as well as reducing the rate of preterm deliveries in our study population.

Notwithstanding these limitations, our findings on occupational activity and SGA, and on working hours, standing, lifting, shift work and preterm delivery, are broadly consistent with earlier research. Previously, in relation to SGA, we described seven studies on working hours, five with RRs close to unity, and eight reports on standing, seven with RRs $\leqslant 1.4$; and in relation to preterm delivery, 11 of 12 studies on lifting carried RRs $<1.4$, while the pooled estimates of $R R$ for prolonged working hours, standing and shift work ranged from 1.2 to $1.3 .^{2}$

In this study we found that trunk bending in late pregnancy (in occupations such as nursing, work with small children (child minders, nannies, teachers), catering, cleaning and shop work) carried a nearly threefold elevation in risk of preterm delivery. Although linked in a few reports with a greater risk of spontaneous abortion, ${ }^{20-22}$ we know of no other study of trunk bending and preterm delivery.

This omission seems important to rectify. Raised intraabdominal pressure, consequent on trunk bending, is a biologically plausible risk factor for preterm labour, especially in the last trimester when space within the abdominal cavity is maximally constrained. Moreover, obesity, a non-occupational cause of raised intra-abdominal pressure, has also been linked with preterm birth, albeit inconsistently in a small literature. ${ }^{23}$ Hence, our observations on trunk bending in late pregnancy require confirmation in other studies.

Additionally, after adjustment for educational attainment and primiparity, we found associations of prolonged working hours with small head circumference. We are aware of only one other occupational study concerning this outcome, in lowincome mothers from Boston. ${ }^{24}$ No significant association was found between standing at work and small head circumference at birth although the odds ratios were elevated and close to statistical significance for exposures in the first two trimesters. Contrary to our finding, an inverse relationship between maternal physical activity (not specifically work activity) in the first two trimesters and small head circumference has been reported in villagers from rural India. ${ }^{16}$ Such inconsistencies and the paucity of reports underscore the need to interpret our data with caution. If true, however, our observations could be clinically relevant, as small head circumference at birth has been linked with a doubling of risks of prevalent coronary heart disease in middle age, ${ }^{10}$ a significantly higher cardiovascular mortality among working-aged men, ${ }^{11}$ and a significantly higher adult systolic blood pressure. ${ }^{7}$ Moreover, in a survey of 50-year olds from Preston, UK, those with impaired glucose tolerance or non-insulin dependent diabetes mellitus had a significantly smaller head circumference at birth. ${ }^{9}$ In most of these studies, definitions of restricted head circumference were less stringent in percentile terms than our own.

The mechanism by which prolonged working hours and other occupational activities might affect birth anthropometrics is unknown, and in the absence of strong prior expectations our findings on head circumference should be viewed only as hypothesis-generating at this stage. Further research is warranted. However, a higher priority is the need to assess further the risks of preterm labour in mothers who bend their trunk late in pregnancy. Our other findings, on preterm delivery and on occupational physical activities and SGA, add to a growing body of evidence that is broadly reassuring to pregnant workers. 
Acknowledgements: We thank the general practitioners and midwives in Southampton for their support. We are grateful to the staff of the Southampton Women's Survey Study Group for all their work in recruiting and interviewing the participants, and processing the data and the samples. Finally, we are grateful to the participants in the Southampton Women's Survey who have given so much time and information about themselves to the Survey.

Funding: Financial support for this work was provided by the UK Medical Research Council, the University of Southampton and the Dunhill Medical Trust.

Competing interests: None.

Provenance and peer review: Not commissioned; externally peer reviewed.

\section{REFERENCES}

1. European Union. Council Directive 92/85/EEC of 19 October 1992 on the introduction of measures to encourage improvements in the safety and health at work of pregnant workers and workers who have recently given birth or are breastfeeding. Available at http://eur-lex.europa.eu/LexUriServ/LexUriServ.do?uri=CELEX:31992L0085:EN:HTML (accessed 10 August 2009).

2. Bonzini M, Coggon D, Palmer KT. Risk of prematurity, low birth weight, and preeclampsia in relation to working hours and physical activities: a systematic review. Occup Environ Med 2007;64:228-43.

3. Berkowitz GS, Papiernik E. Epidemiology of preterm birth. Epidemiol Rev 1993;15:414-43.

4. Moser K, Li L, Power C. Social inequalities in low birth weight in England and Wales: trends and implications for future population health. J Epidemiol Community Health 2003; 57:687-91.

5. Barker DJB, ed. Fetal and infant origins of adult disease. London: BMJ Publishing Group, 1992.

6. Mozurkewich EL, Luke B, Avni M, et al. Working conditions and adverse pregnancy outcome: a meta-analysis. Obstet Gynecol 2000;95:623-34.

7. Barker DJ, Godfrey KM, Osmond C, et al. Maternal and fetal influences on blood pressure. Arch Dis Child 1991;66:1291-5.

8. Barker DJ, Shiell AW, Barker ME, et al. Growth in utero and blood pressure levels in the next generation. J Hypertens 2000;18:843-6.
9. Phipps K, Barker DJ, Hales CN, et al. Fetal growth and impaired glucose tolerance in men and women. Diabetologia 1993;36:225-8.

10. Stein CE, Fall $\mathrm{CH}$, Kumaran $\mathrm{K}$, et al. Fetal growth and coronary heart disease in south India. Lancet 1996;348:1269-73.

11. Barker DJ, Osmond C, Simmonds SJ, et al. The relation of small head circumference and thinness at birth to death from cardiovascular disease in adult life. BMJ 1993;306:422-6.

12. Barker DJ, Martyn CN, Osmond C, et al. Growth in utero and serum cholesterol concentrations in adult life. BMJ 1993:307:1524-7.

13. Inskip HM, Godfrey KM, Robinson SM, et al. Cohort profile: The Southampton Women's Survey. Int J Epidemiol 2006;35:42-8.

14. Cole TJ, Freeman JV, Preece MA. British 1990 growth reference centiles for weight, height, body mass index, and head circumference fitted by maximum penalized likelihood. Stat Med 1998;17:407-29.

15. Royston P. Calculation of unconditional and conditional reference intervals for foetal size and growth from longitudinal measurements. Stat Med 1995;14:1417-36.

16. Rao S, Kanade A, Margetts BM, et al. Maternal activity in relation to birth size in rural India. The Pune Maternal Nutrition Study. Eur J Clin Nutr 2003;57:531-42.

17. Pompeii LA, Savitz DA, Evenson KR, et al. Physical exertion at work and the risk of preterm delivery and small-for-gestational age birth. Obstet Gynecol 2005; 106:1279-88

18. Hatch M, Ji BT, Shu XO, et al. Do standing, lifting, climbing, or long hours of work during pregnancy have an effect on fetal growth? Epidemiology 1997:8:530-6.

19. Axelsson G, Rylander R, Molin I. Outcome of pregnancy in relation to irregular and inconvenient work schedules. Br J Ind Med 1989;46:393-8.

20. Florack EI, Zielhuis GA, Pellegrino JE, et al. Occupational physical activity and the occurrence of spontaneous abortion. Int J Epidemiol 1993;22:878-84.

21. Fenster L, Hubbard AE, Windham GC, et al. A prospective study of work-related physical exertion and spontaneous abortion. Epidemiology 1997;8:66-74.

22. El-Metwalli AG, Badawy AM, El-Baghdadi LA, et al. Occupational physical activity and pregnancy outcome. Eur J Obstet 2001;100:41-5.

23. Galtier-Dereure F, Boegner $\mathrm{C}$, Bringer J. Obesity and pregnancy: complications and costs. Am J Clin Nutr 2000:71:1242S-8S.

24. Zuckerman BS, Frank DA, Hingson R, et al. Impact of maternal work outside the home during pregnancy on neonatal outcome. Pediatrics 1986;77:459-64. 